\title{
Design of Assistance Characteristics Curve for Electric Power Steering System
}

\author{
Shaosong Li, Ren Sheng, Gaojian Cui, Shunhang Zheng, Zhixin Yu* and Xiaohui Lu \\ School of Mechanical and Electrical Engineering, Changchun University of Technology, China; \\ ${ }^{*}$ Corresponding author
}

\begin{abstract}
Electric power steering (EPS) system can not only provide steering power and lighten the burden of the driver's manipulation, but also improve vehicle steering performance and driving comfort, thus improving vehicle active safety. However, in the process of EPS system development, the determination of EPS assistance characteristics curve mainly depends on the driver's subjective evaluation, which needs more time in real vehicle debugging and calibration. In this paper, a novel design method of EPS assistance characteristics curve is proposed. Firstly, the relationship between EPS assistance torque and the driver's steering torque is determined based on the steering wheel torque characteristics of passenger cars; Secondly, a speed interval division method of EPS assistance map is put forward based on the static lateral acceleration gain; Finally, a threedimensional map that electric control unit demands is drawn and its effect is verified through the real vehicle test.
\end{abstract}

Keywords-electric power steering system; assistance characteristic curve; speed interval division; static lateral acceleration gain

\section{INTRODUCTION}

The design of EPS assistance characteristics curve is to determine the change rule of EPS assistance torque according to vehicle speeds and the driver's steering torque. Whether the designed EPS assistance characteristics curve is reasonable will affect the vehicle steering performance [1]. In theory, the EPS assistance characteristics curve should be able to coordinate the relationship between steering portability and road feel. With the increase of the vehicle speed, the EPS assistance torque should gradually become smaller to ensure the steering stability at high speed [2]. However, in the process of EPS system development, the determination of EPS control parameters mainly depends on debugging person's subjective feeling, which needs a longer period.

In literature [3] the decreasing exponential function is designed to express EPS assistance characteristics curve. However there are some difficulties to realize it in EPS controller. In literature [4] the assistance torque is determined based on the lateral force ratio in front wheel relative to driver's steering torque, which can follow the vehicle speed and the load change well. But there is a certain difficulty in the acquisition of front wheel lateral force. It is pointed out in literature [5] that the driver's steering torque should increase gradually as vehicle speed increased.

In this paper, EPS assistance torque according to driver's steering torque is determined based on the steering wheel torque characteristics of passenger cars. And the interval division of vehicle speed is determined based on the static lateral acceleration gain. Finally, a three-dimensional map of EPS assistance characteristics curve is drawn. The experiment results showed that the EPS vehicle can steer flexible at low speed and steer steadily at high speed.

\section{EPS SYSTEM DYNAMIC MODEL}

Model simulation is a good means to design the assistance characteristics curve of EPS. As shown in Figure I, the driver's steering torque is detected through a torque sensor placed between the steering wheel and assist motor. The actual current of EPS motor is detected through a current sensor. The desired assistance torque is determined based on the driver's steering torque and vehicle speed. Both the EPS assistance torque and the driver's steering torque are applied to conquer the resistance torque of steering system.

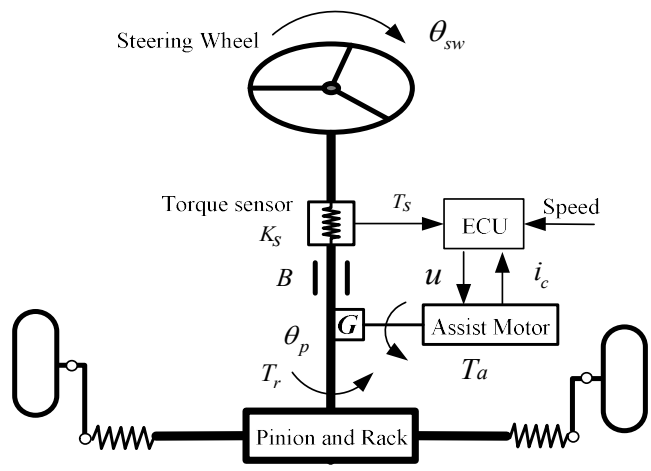

FIGUREI. SCHEME OF EPS SYSTEM

The dynamic equations about the steering system are presented as follows [6]:

$$
\begin{gathered}
T_{s}+T_{a}-T_{r}=J \cdot \ddot{\theta}_{p}+B \cdot \dot{\theta}_{p}+T_{\text {friction }} \\
T_{s}=K_{s} \cdot\left(\theta_{s w}-\theta_{p}\right) \\
T_{a}=K \cdot G \cdot T_{s} \\
u=R_{c} \cdot i_{c}+K_{c} \cdot \dot{\theta}_{m}+L_{c} \cdot \frac{d i_{c}}{d t} \\
\dot{\theta}_{m}=G \cdot \dot{\theta}_{p}
\end{gathered}
$$

Where $T_{\mathrm{s}}$ is the steering wheel torque measured by torque sensor. $T_{a}$ is the torque generated by motor. $T_{r}$ denotes the 
resistance torque from road wheels. $J, B$ and $T_{\text {friction }}$ are inertia, damping coefficient and friction torque of steering system. $\theta_{p}$ represents the rotation angle of steering pinion position. $\theta_{s w}$ denotes the rotation angle of steering wheel. $K_{s}$ is the stiffness coefficient of torque sensor. $K$ is EPS assistance gain. $G$ is the reduction ratio of motor. $u$ is the motor armature voltage. $R_{c}$ is the electric resistance of motor. $i_{c}$ is the motor armature current. $K_{c}$ is the motor EMF coefficient. $\theta_{m}$ denotes the rotation angle of motor. $L_{c}$ is the electric inductance of motor.

\section{Design of EPS Assistance Characteristics Curve AT SPECIFIC SPEED}

\section{A. Design Basis}

The steering wheel torque characteristics, including steering feeling, force feedback, steering burden and so on, mainly describes the variation characteristics of steering torque relative to other vehicle state parameters. The steering wheel torque characteristics is mainly to research on-center handling performance, as well as the torque characteristics in linear and nonlinear range.

The design of EPS assistance characteristics curve is mainly to determine the amplitude, slope and curvature of EPS assistance curve. And the the ideal steering wheel torque characteristics should possess the following requirements:

1) The steady-state steering wheel torque should increase proportionally with vehicle speed and lateral acceleration in linear range. When vehicle tire is close to the adhesion limit, the steering wheel torque should be decreased with the increase of lateral acceleration.

2) The on-center handling performance mainly represents the change of steering torque relative to steering wheel angle or lateral acceleration at high speed and small lateral acceleration. On-center handling performance is mainly divided into the following three parts: time delay, sensitivity and road feeling. In parking condition, the maximum steering wheel torque should be less than $4.5 \mathrm{Nm}$.

\section{B. Design of EPS Assistance Characteristics Curve in the Linear and Nonlinear Range}

In this paper the design method of EPS assistance characteristics curve in linear and nonlinear range at $100 \mathrm{~km} / \mathrm{h}$ is proposed. In literature [7], the steering wheel torque characteristics for Chinese drivers under different vehicle speeds and lateral acceleration are researched based on driving simulator. According to the research results, the target steering wheel torque is set as $2.6 \mathrm{Nm}$ when lateral acceleration is $0.1 \mathrm{~g}$ and the target value is set as $3.6 \mathrm{Nm}$ when lateral acceleration is $0.3 \mathrm{~g}$.

To achieve the target value shown in Figure III the slope and amplitude of EPS assistance torque in Figure II needs to be regulated. It can be seen from Figure III that the steering wheel torque increases linearly when lateral acceleration is at the range of $0.1 \mathrm{~g} \sim 0.42 \mathrm{~g}$. The steering wheel torque increases nonlinearly when lateral acceleration is at the range of $0.42 \mathrm{~g} \sim 0.65 \mathrm{~g}$. And the steering wheel torque decreases when lateral acceleration is greater than $0.65 \mathrm{~g}$. Therefore, the steering wheel torque characteristics of EPS in linear and nonlinear range can represent the change of lateral acceleration and tire adhesion.

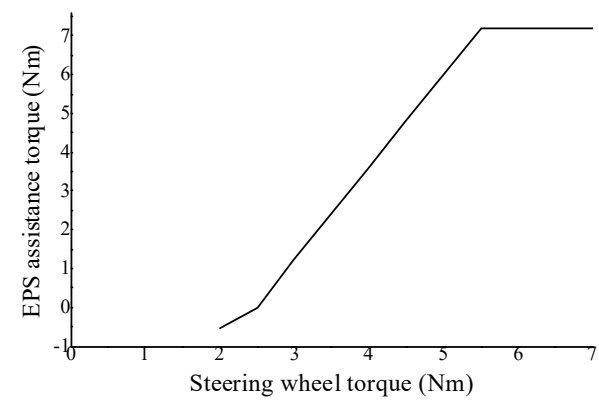

FIGURE II. EPS ASSISTANCE TORQUE AT

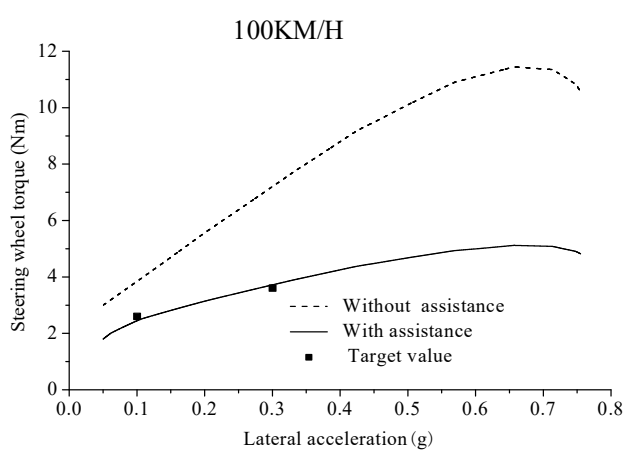

FIGURE III. STEERING WHEEL TORQUE AT 100KM/H

\section{Design of Eps Assistance Characteristics Curve on- Center}

To design the EPS assistance characteristics curve oncenter, three types of curves are provided in Figure IV: one is to increase EPS assistance amplitude and the other is to increase EPS assistance slope. Simulation results are shown in Figure V and Figure VI. It can be seen that the EPS assistance amplitude can directly affect the magnitude of steering wheel torque, and the EPS assistance slope can directly affect the gradient of steering wheel torque. The ideal gradient and steering wheel torque can be obtained through debugging the slope and amplitude of EPS assistance characteristics curve oncenter.

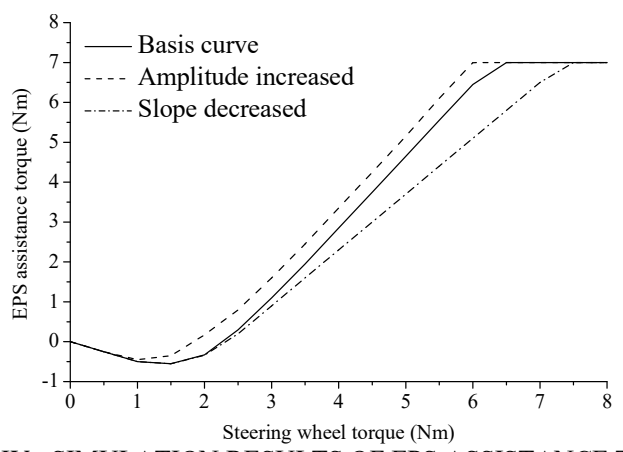

FIGURE IV. SIMULATION RESULTS OF EPS ASSISTANCE TORQUE 


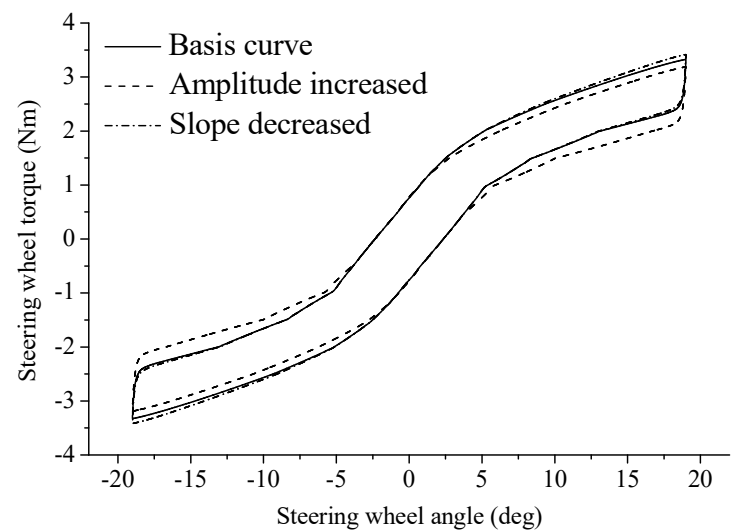

FIGURE V. SIMULATION RESULTS OF STEERING WHEEL TORQUE

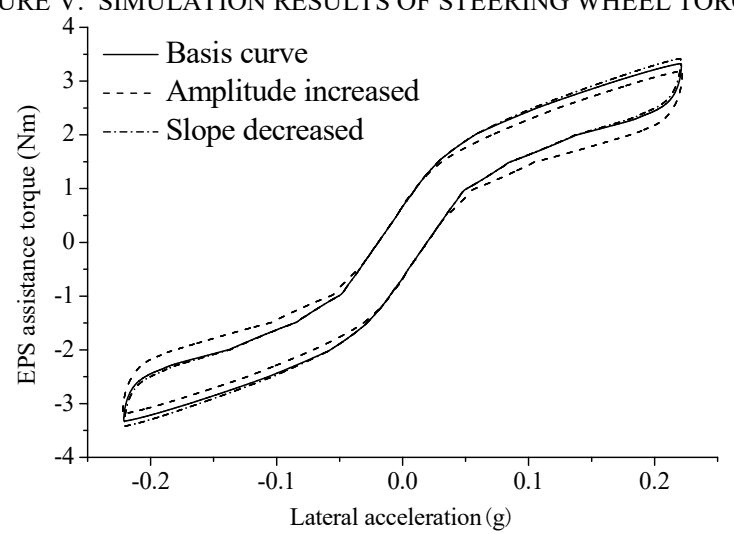

FIGURE VI. STEERING WHEEL TORQUE ACCORDING TO LATERAL ACCELERATION

After repeated debugging, the road feeling and steering wheel torque can be similar to the target vehicle. The design method of the EPS assistance characteristic at the speed of $100 \mathrm{~km} / \mathrm{h}$ can be extended to other vehicle speeds.

\section{SPEED INTERVAL DiVISION OF EPS ASSISTANCE CHARACTERISTICS CURVE}

The design of EPS assistance characteristics curve is mainly to determine the steering wheel torque characteristics in steady state. The dynamic steering wheel torque characteristics is mainly affected by the damping and inertia of steering system, which are determined based on the driver's subjective evaluation and will not be researched in this paper. Therefore, equation (1) can be rewritten as followed without considering the damping and inertia of steering system.

$$
T_{s}+T_{a}=T_{r}+T_{\text {friction }}
$$

It can be seen from equation (6) that when EPS assistance torque is zero, the steering wheel torque equals the resistance torque from road wheels which can represent the change characteristics of vehicle lateral acceleration. Therefore, the curve of static lateral acceleration gain shown in Figure VII can be used to represent the change characteristics of steering wheel torque. It is pointed out in literature [8] that the steering wheel torque increases linearly with the vehicle speed increasing. Therefore, the division principle of vehicle speed based on static lateral acceleration gain is as follows: The curve static lateral acceleration gain is densely divided into many linear zones in the nonlinear range; In the linear range the curve of static lateral acceleration gain is unnecessarily divided.

It can be seen in Figure VII that the curve of static lateral acceleration gain is divided into five zones (from A to E) based on its slope according to vehicle speed. In zone A dense speed points are set to ensure that the steering wheel torque can change smoothly in parking condition. In zone B or D dense speed points are also set because of the nonlinear change characteristics of static lateral acceleration gain. In zone $\mathrm{E}$ the static lateral acceleration gain represents weak nonlinear change and sparse speed points are set. When the vehicle speed belongs to zone $\mathrm{C}$, the static lateral acceleration gain represents linear characteristics and vehicle speed is unnecessarily divided in this zone.

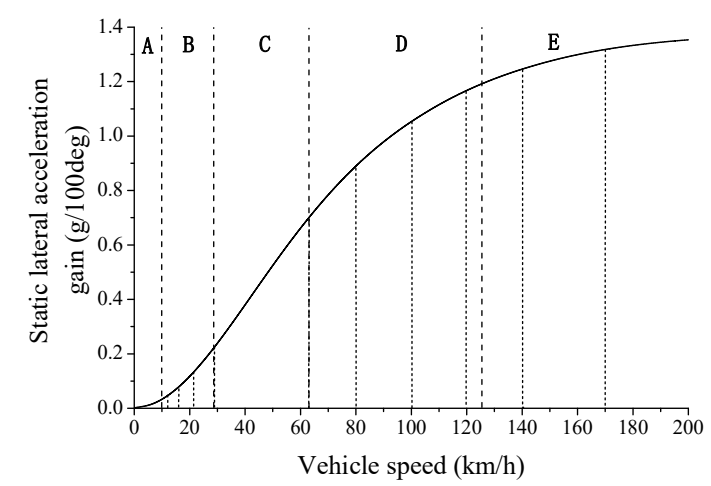

FIGURE VII. SPEED INTERVAL DIVISION FOR STATIC LATERAL
ACCELERATION GAIN

The EPS assistance torque at specific vehicle speed is firstly determined based on the design method in section II. The EPS assistance torque except these specific vehicle speeds can be determined through linear interpolation. Finally, the whole EPS assistance characteristics curve can be obtained and the three-dimensional map is shown in Figure VIII.

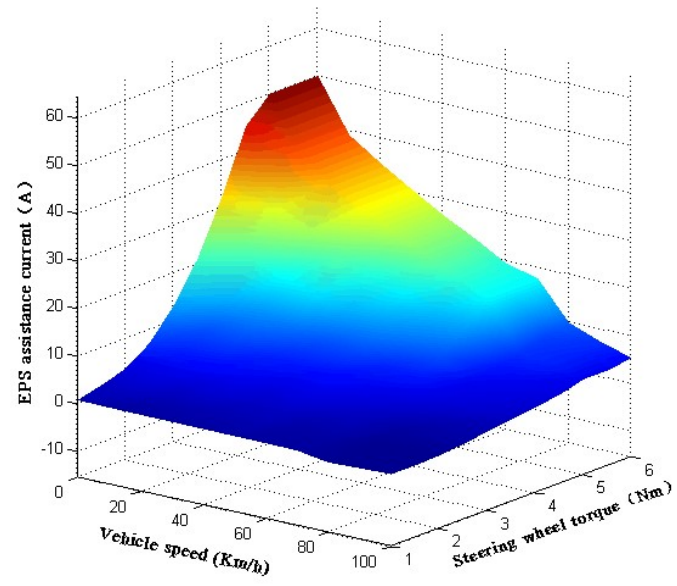

FIGURE VIII. THREE-MAP OF EPS ASSISTANCE CHARACTERISTICS CURVE VEHICLE TEST 


\section{VERIFICATION}

In order to validate the proposed design method, the vehicle with modified EPS system has been set up in the laboratory (see Figure IX). And the measuring equipment and parameters are shown in TableI.

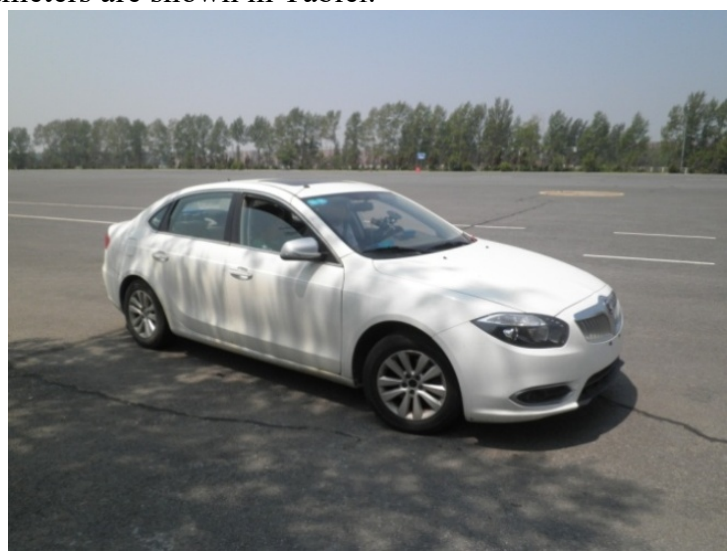

FIGURE IX. TEST VEHICLE WITH EPS

TABLE I. EQUIPMENT AND PARAMETERS

\begin{tabular}{|c|c|}
\hline & $\pm 1080^{\circ}$ \\
\hline $\begin{array}{c}\text { Steering robot for steering torque } \\
\text { and steering angle measurement }\end{array}$ & $\pm 50 \mathrm{Nm}$ \\
\cline { 2 - 2 } & $0-50 \mathrm{~m} / \mathrm{s}$ \\
\hline $\begin{array}{c}\text { Speedometer for vehicle speed } \\
\text { measurement }\end{array}$ & $\pm 9.8 \mathrm{~m} / \mathrm{s}^{2}$ \\
\hline $\begin{array}{c}\text { Gyroscope for lateral } \\
\text { acceleration measurement }\end{array}$ & \\
\hline
\end{tabular}

\section{A. On-center Steering Test}

To validate the steering wheel torque characteristics oncenter, the vehicle is driving at the speed of $100 \mathrm{~km} / \mathrm{h}$ and the steering wheel angle is $16^{\circ} \sin (2 \pi f t)$, where $f$ is fixed at $0.2 \mathrm{~Hz}$. The test results are shown in Figure X and Figure XI. And the objective value of handling performance on-center is shown in Table II. It can be seen that the handling performances of EPS system are similar to the objective value of target vehicle.

TABLE II. VEHICLE TEST RESULTS

\begin{tabular}{|c|c|c|}
\hline Objective value & EPS vehicle & $\begin{array}{l}\text { Target } \\
\text { value }\end{array}$ \\
\hline Lateral acceleration at $0 \mathrm{Nm}\left(\mathrm{m} / \mathrm{s}^{2}\right)$ & 0.63 & 0.53 \\
\hline $\begin{array}{c}\text { Frictional loss torque of steering } \\
\text { system (deg) }\end{array}$ & 7.91 & 5.48 \\
\hline $\begin{array}{l}\text { Torque gradient of steering wheel } \\
\text { at } 0 \mathrm{~m} / \mathrm{s}^{2}\left(\mathrm{Nm} /\left(\mathrm{m} / \mathrm{s}^{2}\right)\right)\end{array}$ & 1.87 & 1.97 \\
\hline Steering torque at $1 \mathrm{~m} / \mathrm{s}^{2}(\mathrm{Nm})$ & 1.95 & 2.04 \\
\hline
\end{tabular}

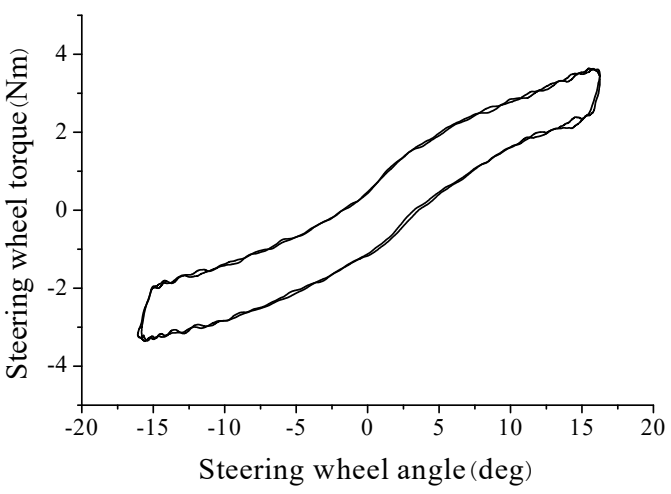

FIGURE X. STEERING WHEEL TORQUE ACCORDING TO LATERAL ACCELERATION

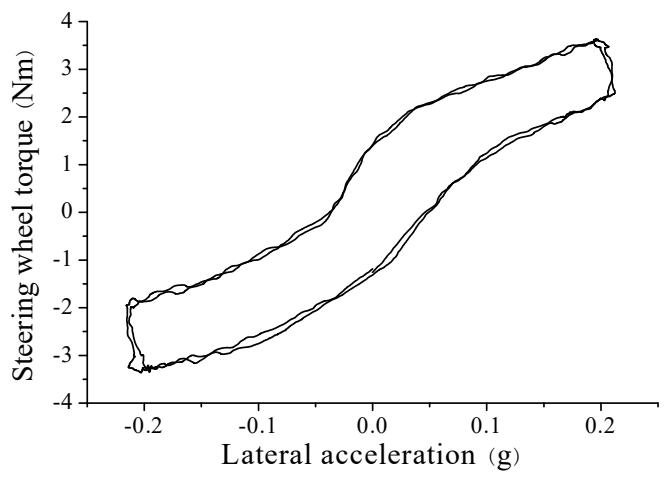

FIGURE XI. STEERING WHEEL TORQUE ACCORDING TO STEERING WHEEL ANGLE

\section{B. Dynamic Steering Test}

In dynamic steering test, the vehicle speed changes from $20 \mathrm{~km} / \mathrm{h}$ to $90 \mathrm{~km} / \mathrm{h}$ and the speed interval is $10 \mathrm{~km} / \mathrm{h}$. At each specific speed, the driver offers sinusoidal input on the steering wheel and the amplitude of steering wheel angle is limited to $35 \mathrm{deg}$. The steering wheel torque at $30 \mathrm{deg}$ is recorded. The curve of steering wheel torque according to vehicle speed is shown in Figure XII. It can be seen that the steering wheel torque increases linearly with the vehicle speed increasing and there is no torque fluctuation in dynamic steering test.

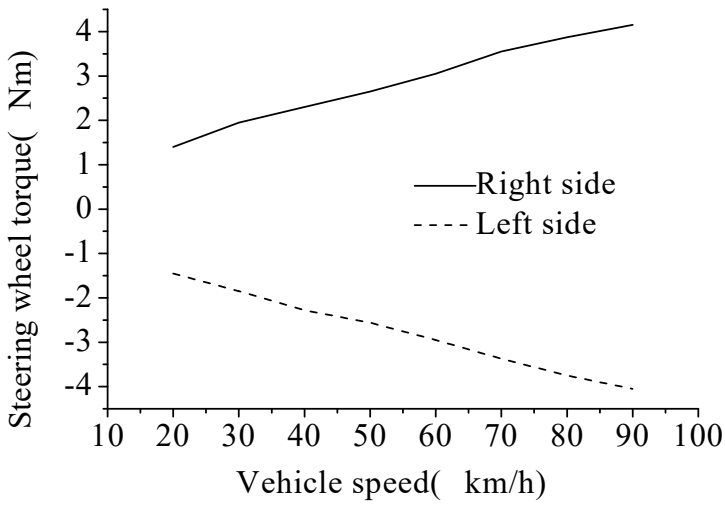

FIGURE XII. STEERING WHEEL TORQUE ACCORDING TO VEHICLE SPEED 


\section{Steering Test in Parking Condition}

To validate the steering wheel torque characteristics in parking condition, EPS vehicle is tested at the speed of 10 $\mathrm{km} / \mathrm{h}$. Firstly, the driver rotates the steering wheel from its center position to its right limit position with the rotational speed $10 \sim 15 \mathrm{r} / \mathrm{min}$. Secondly, the driver rotates the steering wheel to its left limit position with the same rotational speed. Finally the steering wheel is rotated to its initial position. The steering wheel torque relative to steering wheel angle is shown in Figure XIII. It can be seen that the steering wheel torque at $70 \%$ of the maximum steering wheel angle is $3.73 \mathrm{Nm}$, which represents good portability in parking condition.

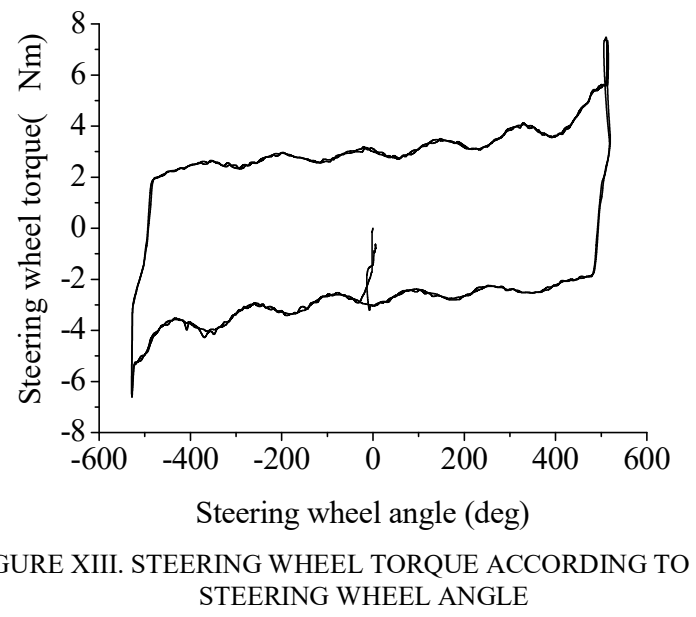

\section{CONCLUSIONS}

The feasibility of EPS assistance characteristics curve which can not only effectively lighten the driver's steering burden but also improve steering performance has been demonstrated. EPS assistance torque at specific vehicle speed is determined based on the objective index of steering wheel torque characteristics. Vehicle speed is divided based on the static lateral acceleration gain. Finally, a three-dimensional map is drawn and its validity is further strengthened through real vehicle test.

\section{ACKNOWLEDGMENTS}

The work is supported by the National Nature Science Foundation of China (No.61603060), by the Jilin Province Science and Technology Found for Young Scholars (No.20170520097JH; No.2016052- 0106JH), and by the Key Technology and Development Program of Jilin Province (No.20170201005GX), and by the science and technology planning project of Changchun city (No. 16CX21).

\section{REFERENCES}

[1] G. B. Shi, Simulation of the Assist Characteristic and Research on the Control Strategy of Electric Power-Assisted Steering [D]. Changchun: Jilin University, 2002.

[2] T. Meng, Zh. P. Yu and H. Chen, et al. Study on Control Strategy of Electric Power Steering And the Test[J]. Automobile Technology, 2005

[3] T. M. Xiang, J. M. Yi and Q. Fang, The Assistance Characteristics Curve Design of EPS[J]. Journal of xihua university (natural science edition), 2009.
[4] X. D. Liu, Y D Liu, and M J. Determination Method of Assisted Characteristics for Electric Power Steering of Vehicle[J]. Journal of Wuhan University of Technology, 2009.

[5] G. Bertollini and R. Hogan, Applying Driving Simulation to Quantify Steering Effort Preference as a Function of Vehicle Speed[J]. SAE Technical Paper, 1999.

[6] M. Kurishige, S. Wada, T. Kifuku, Inoue N. et al. A New EPS Control Strategy to Improve Steering Wheel Returnability[J]. SAE Technical Paper 2000.

[7] CH. F. Zong, L. Mai, D. P. Wang and Y. J. Li, Study On Steering Effort Preference Of Drivers Based On Driving Simulator[J]. China Mechanical Engineering, 2007.

[8] X. Wang, Research on Bilateral Control and Variable Ratio Characteristics for Steer-by-Wire Automobile[D]. Changchun: Jilin University, 2013 